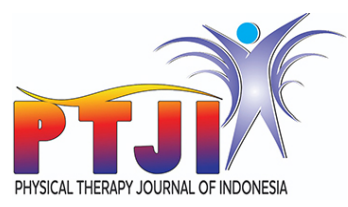

\title{
The Relationships Between Sewing and Forward Head Posture
}

\author{
Diky Krisnanda Sugianto ${ }^{1 *}$, Safun Rahmanto², Dimas Sondang Irawan ${ }^{2}$
}

\section{ABSTRACT}

Introduction: The working attitude that is often done by human beings in doing work among others standing, sitting, bent, squat, walking, and others. Attitudes such as work are done hanging from the condition of the system's existing work. Forward head posture is the incident common much going on in modern times. It is described as a gesture of brought the heads of forward from the middle part of the shoulder. Head of moving forward, so the center of gravity shifted. To compensate this shift in the center of gravity, drift the upper body backward and shoulders slipped to future that head gets a move into the anterior than vertebrae. Every activity daily life needs a posture certain to be maintained. Any deviation from the normal pattern posture affecting the joints and muscle, so as to cause the pathological condition. An imbalance in the muscles causing shortening of fiber or lengthening next leads to changes in posture. This research aims to understand the relationship that activity sew against forwarding head posture (FHP) at a tailor.

Methods: This study using design cross-sectional involving 30 respondents using purposive sampling. The data from respondents carried out using a quick check the exposure (QEC) and then in test measurements forward head posture. We analyzed the data by chisquare.

Results: The statistics conducted by the SPSS-24 test using chisquare showed significantly ( $P$ value $=0,018$ ). Where if the signs have been less than 0.05 so that $h 1$ is accepted and $h 0$ is rejected. Conclusion: There is a correlation that activity sew against forwarding head posture on a the tailors.
'Bachelor and Professional Program of Physical Therapy, College of Health Science, Universitas Muhammadiyah Malang

2Department of Physical Therapy, College of Health Science, Universitas Muhammadiyah Malang

\section{*Corresponding:} Diky Krisnada Sugianto; Bachelor and Professional Program of Physical Therapy, College of Health Science, Universitas Muhammadiyah Malang; dikykrisnanda@gmail.com
Received : 2020-02-06 Accepted : 2020-04-02 Published : 2020-05-15

Keywords: forward head posture, sewing activity, work attitude. Cite this Article: Sugianto, D.K., Rahmanto, S., Irawan, D.S. 2020. The Relationships Between Sewing and Forward Head Posture. Physical Therapy Journal of Indonesia 1(1): 9-12.

\section{INTRODUCTION}

Work attitudes that are often performed by humans in doing work include standing, sitting, bending, squatting, walking, and others. The working attitude is carried out depending on the conditions of the existing work system. If the condition of the work system is not healthy will cause work accidents due to unsafe work. Sitting in a long time will cause burnout and fatigue, because when standing upright, the burden is influenced by gravity working in a vertical straight line through the center of the body held by the spine and projected on both legs, thus the center of body weight is in front of the spine, resulting in a moment of force that causes the body to tend to fall forward. ${ }^{1}$

Work with a static work attitude sitting and sitting bent for a long time also illustrated in the work tailor. ${ }^{1}$ In a recent study, the weight supported by the spine increase dramatically when the head drops forward to varying degrees. In an adult's head, it weighs between $10-12$ pounds in a neutral position. When the head is tilted forward 15 degrees, the strength of the feeling of heaviness in the neck can surge to 27 pounds, at 20 degrees can reach 40 pounds, at 45 degrees can reach 49 pounds, and at 60 degrees can reach 60 pounds. At an angle of 90 degrees, model predictions cannot be deciphered. ${ }^{1}$

The workers who do work for a long time or work at a desk with a bent position for too long cause disturbances in tension and stretching muscles and ligaments around the neck. Body posture that is usually performed on static workers is forward head posture (FHP). Forward head posture is a common occurrence in many modern times for tailor workers. This is described as the attitude of bringing the head forward from the middle of the shoulder. the head moves forward, so the center of gravity shifts. To compensate for this shift in the center of gravity, the upper body drift backward and the shoulders slump forward so that the head is more anterior than the vertebra. ${ }^{2}$

Any deviation from the normal posture pattern affects the joints and muscles, thus causing a pathological condition. Imbalance in muscle causes shortening or lengthening of the fibers Further leading to changes in posture. Forward head posture (FHP) is the most common deviation from the normal curvature of the spine in the neck. ${ }^{3}$ Factors in the examination of posture are very important 
in measuring posture, for example, the problem of musculoskeletal pain can affect posture because the body moves to reach a level of body comfort can change according to the height of the pain, besides anatomical structure in scoliosis disorders and leg discrepancy can also affect results of examination of subjects on posture. ${ }^{4}$

The sewing business is an effort to convert textiles into clothing, bags and other textile products. Clothing is a basic human need while the industry and micro-small businesses are so numerous that researchers want to know the relationship of sewing activities to the forward head posture of tailors.

\section{METHODS}

This study is a descriptive observational with a crosssectional approach. The sampling technique used in this study is a purposive sampling technique with 30 respondents. To find out the relationship between the independent variables with the dependent variable the chi-square statistical test was used. The result of the chi-square did not meet the results of the analysis switched to using the fisher's exact test,

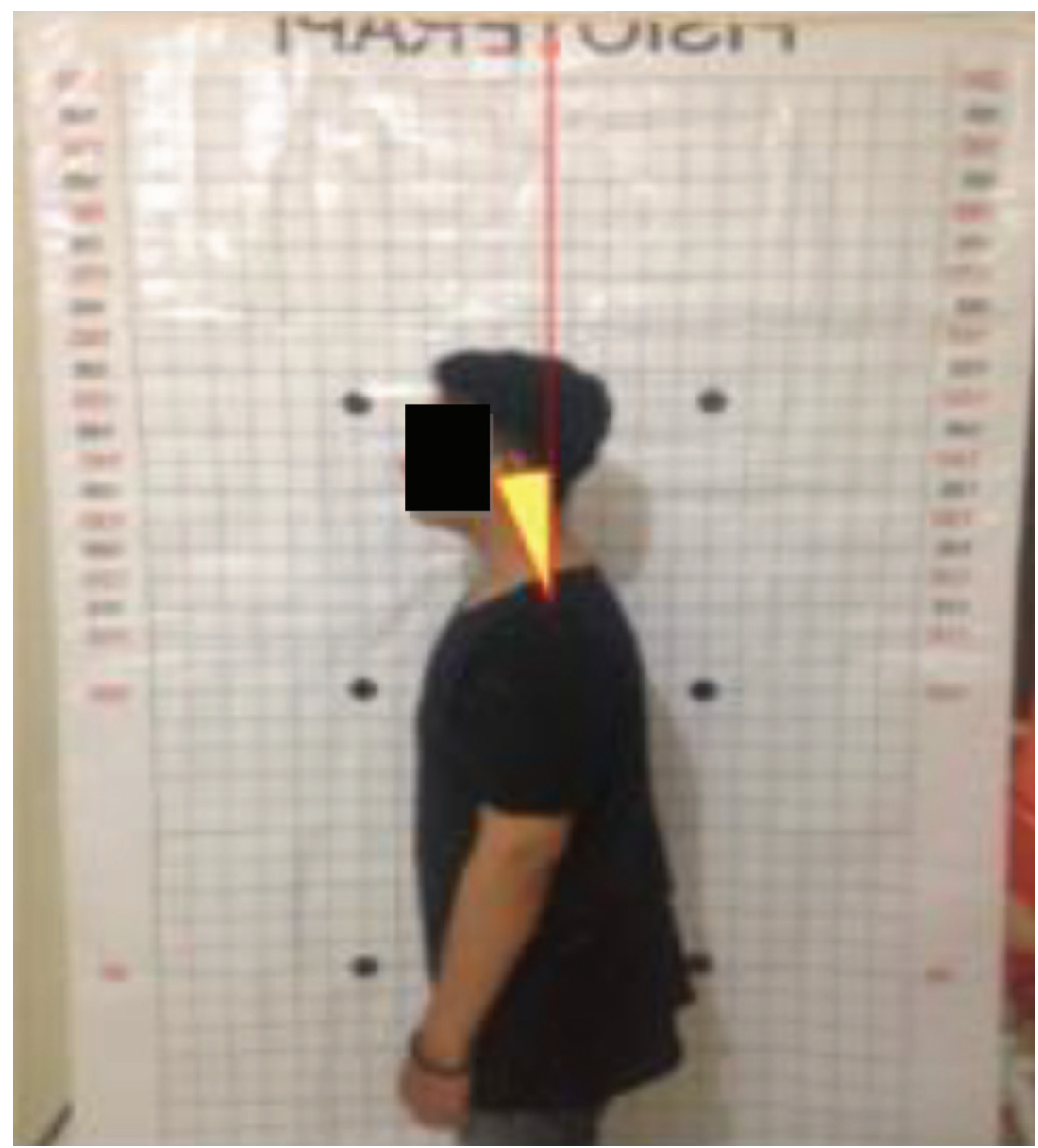

Figure 1. Forward head posture assessment with $(a=0.05)$. Then the input value $(P)$ of the data is compared with the value of a. If the value of zig (P) $>$ (a) then there is no relationship, whereas if the value of $\operatorname{zig}(\mathrm{P})<(\mathrm{a})$, then there is a relationship.

\section{RESULTS}

The population in the study included 22 male respondents $(73 \%)$ and 8 female respondents (27\%). In terms of age, the number of respondents consisted of 17-25 years were 5 people (16\%), 2635 years were 8 people (27\%), $36-45$ years were 8 people (27\%), $46-55$ years were 9 people (30\%). The respondents carry out their work in several working time ranges of less than 2 hours (no one), 2-4 hours (1 respondent), and more than 4 hours (29 respondents). The working period of respondents at less than 5 years (1 respondent), 6-10 years (12 respondents), and more than 10 years (17 respondents).

The correlation between sew activities to the FHP showed bad conditions of 20 respondents, 15 respondents showed a straight condition and FHP there were 5 respondents, whereas in sew activities very bad from 10 respondents showed a straight condition there were 3 respondents and FHP there were 7 respondents.

The Fisher exact tests conducted by the SPSS program revealed there is a significant number (0.045) which means less than 0.05 , there is a correlation of sewing activities against forwarding head posture on the tailors.

\section{DISCUSSION}

FHP is the most common deviation from the normal curvature of the spine in the neck. The higher age shows the influence of pathological disorders of posture, high working time and work period without being balanced with good work attitude increase the risk factors for musculoskeletal disorders and posture in the tailor. ${ }^{3}$

The results of the prevalence of the characteristics of age, length of service and working time of respondents showed that age is a risk factor for the occurrence of musculoskeletal disorders and the emergence of postural problems. In the higher age range, more and more disorders arise and physiological and pathological changes, as a person ages, the possibility of anatomical and functional decline. $^{4}$

The increasing age number and poor work attitude in the accompaniment in a long time will result in physiological and pathological changes including joint system on synovial joints in the form of changes in the uneven surface of the joints, fibrillation and the formation of cracks and grooves 
in the surface of the cartilage, hyaline cartilage erosion causes bone eburnation and cyst formation in the subchondral cavity and bone marrow so that this can be called a pathological disorder, but it is agreed that said pathological disorders if there is additional stress such as trauma or the joints bearing the burden. ${ }^{5}$

The results of the average work time showed that respondents have work time above 4 hours per day, this has the effect of a high level of worker fatigue. While the respondent's tenure shows workers over 10 years have a change in the physiology of neck posture. ${ }^{6}$ Forward head posture habits accompanied by increasing age also affect changes in the structure of the cervical bone which is getting worse, this is shown from the correlation of age-related to

Table 1. The respondent information

\begin{tabular}{cccc}
\hline Respondent Characteristics & Total & Percentage (100\%) \\
\hline Mex & Female & 82 & 73 \\
& $17-25$ & 5 & 27 \\
& $26-35$ & 8 & 27 \\
Age & $36-45$ & 8 & 27 \\
& $46-55$ & 9 & 30 \\
& $56-60$ & 0 & 0 \\
& $<2$ & 0 & 0 \\
Work Time (hour) & $2-4$ & 1 & 3 \\
& $>4$ & 29 & 97 \\
& $<5$ & 1 & 3 \\
\hline
\end{tabular}

Table 2. Correlation between sew activities and forward head posture

\begin{tabular}{cccc}
\hline \multirow{2}{*}{ Sew Activities } & \multicolumn{3}{c}{ Forward head posture } \\
& Yes & No & Total \\
\hline Bad & 5 & 15 & 20 \\
Very Bad & 7 & 3 & 10 \\
Total & 12 & 18 & 30 \\
\hline
\end{tabular}

Table 3. The result of Fisher's exact test

\begin{tabular}{ccc}
\hline & Exact sig & Summary \\
\hline Uji Fisher's exact test & 0,045 & $<0,05$ \\
$\mathrm{n}=30$ & & \\
\hline
\end{tabular}

forward head posture, physiological changes in muscles occur along with respondent habits and as age increases it also affects physiology, i.e. bone destruction and bone formation also slows down. ${ }^{5}$

The longer time worked plus the forward head posture attitude shows subjective complaints of neck pain and in accordance with research conducted in which the average person is responsive in doing work tends to bend the head forward forwards over the shoulder. In an adult's head, the weighs between 10-12 pounds in a neutral position. When the head is tilted forward 15 degrees, the strength of the feeling of heaviness in the neck can surge to 27 pounds, at 20 degrees can reach 40 pounds, at 45 degrees can reach 49 pounds, and at 60 degrees can reach 60 pounds. In this case, if it happened continuously, it will certainly cause discomfort in the neck. Neck pain will arise and cause some pathological changes including prominent discs and neck muscle will be stretched. ${ }^{7}$

The correlation between the influence of the length of service of respondents indicates that the work period above has a higher incidence of forwarding head posture disturbance, so it is in accordance with the interpretation of the respondent's increasing age. ${ }^{8}$

Any deviation from the normal postural pattern affects the joints and muscles, thus causing a pathological condition. ${ }^{9}$ Imbalance in muscle causes shortening or extension of the fibers further leading to postural changes. Forward head posture is a change in anterior and posterior muscle length, and a prolonged FHP position can increase cervical burden because the head load increases when the head tends to go forward so that it can affect changes in muscle length condition, cervical bone structure that affects joint stability and pain in the neck region so in a long time can result in worse posture conditions in the FHP. ${ }^{10}$

\section{CONCLUSION}

Based on the results of this study, correlation sew activities to the forward head posture (FHP) in the tailors, it can be concluded that the work attitudes shown during sewing activities showed poor work activities of 20 respondents (66\%), very poor work activities of 10 respondents (34\%), and is done in a work time of more than 4 hours per day from a total of 30 respondents. The emergence of interference with FHP in the straight condition there are 18 respondents (60\%), and FHP there are 12 respondents $(40 \%)$ of the total 30 respondents. There is a correlation between sewing activities and FHP for tailors. 


\section{CONFLICT OF INTEREST}

No any benefit was received by the authors or authors' affiliations from any commercial party.

\section{ACKNOWLEDGEMENT}

The authors want to thank the head of Department of Physical Therapy, College of Health Science, Muhammadiyah Malang, Indonesia for the guidance and support during this study period. This study received no funding from any institution.

\section{AUTHOR CONTRIBUTIONS}

DK carried out the study design, data collection, and drafting the article; SR and DSI conceived the study design, data interpretation, and drafting the article.

\section{REFERENCES:}

1. Andreani M,U,D. Paskarini, A. sikap kerja yang berhubungan dengan keluhan subjektif pada penjahit di jalan patua Surabaya. Departemen Keselamatan dan Kesehatan Kerja. Fakultas Kesehatan Masyarakat Universitas Airlangga

2. Junhyuk Park, Kwangho Kim, Namkang Kim, Inwon Choi, Sujung Lee, Sajin Tak and Jongeun Yim. (2015). A Comparison of Cervical Flexion, Pain, and Clinical Depression in Frequency of Smartphone Use. International Journal of Bio-Science and Bio-Technology. Vol.7, No.3, pp.183-190.
3. Thakur D.,Motimath B., Raghavendra M. (2016). Forward head posture correction versus shoulder stabilization exercises effect on scapular dyskinesia and shoulder proprioception in athletes: an experimental study. Int J Physiother. Vol 3(2), 197-203.

4. Elaheh Sajjadi, Gholam Reza Olyaei, Saeed Talebian, Mohammad-Reza Hadian, Shohre Jalaie. (2014). The effect of forward head posture on cervical joint position sense. Journal of Paramedical Sciences (JPS). Vol.5, No.4

5. Boedhi darmojo, R. Martono, hadi H. (2014). Buku ajar Geriatri. Jakarta. Badan penerbit FKUI.

6. Young Lee, MI, PT, PhD , Yong Lee hai, MS, dan Sik Yong, min, MS. (2014). Characteristics of Cervical Position Sense in Subjects with Forward Head Posture. The Society of Physical Therapy Science. Published by IPEC Inc. 26: 1741-1743.

7. David, Geoffrey, Woods Valerie, Guangyan Lie, Buckle Peter. (2007). The development of the quick exposure check (QEC) for assessing exposure to risk factor for work related musculoskeletal disorder. Elsevier. 57-59.

8. Johnson J. (2012). Postural assessment. United state of America. Human kinetic.

9. Inae Caroline Gadotti MSc PT. Daniela Aparecida BiasottoGonzalez PhD. (2008). Sensitivity of clinical assessments of sagittal head posture. Journal of Evaluation in Clinical Practice.

10. Nejati, P. lotfian, S. moezy, A. mina, N.( 2015). the study of correlation between forward head posture and neck pain in iranian office workers. International Journal of Occupational Medicine and Environmental Health. Vol 28:295 - 303.

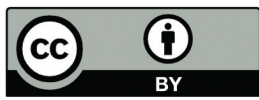

This work is licensed under a Creative Commons Attribution 